Article

\title{
A Phase-Shift-Modulated LLC-Resonant Micro-Inverter Based on Fixed Frequency Predictive-MPPT
}

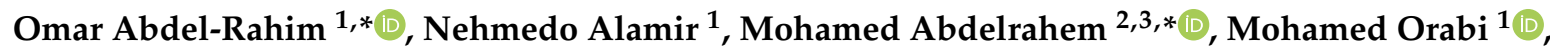 \\ Ralph Kennel ${ }^{2}$ and Mohamed A. Ismeil ${ }^{2,4}$ \\ 1 Aswan Power Electronics Applications Research Center (APEARC), Faculty of Engineering, Aswan \\ University, Aswan 81542, Egypt; nehmedo.alamir@aswu.edu.eg (N.A.); morabi@apearc.aswu.edu.eg (M.O.) \\ 2 Institute for Electrical Drive Systems and Power Electronics (EAL), Technical University of Munich (TUM), \\ 80333 Munich, Germany; ralph.kennel@tum.de (R.K.); melzanaty@apearc.aswu.edu.eg (M.A.I.) \\ 3 Electrical Engineering Department, Faculty of Engineering, Assiut University, Assiut 71516, Egypt \\ 4 Electrical Engineering Departement, Faculty of Engineering, South Valley University, Qena 83523, Egypt \\ * Correspondence: o.abdelrahim@aswu.edu.eg (O.A.-R.); mohamed.abdelrahem@tum.de (M.A.)
}

Received: 17 February 2020; Accepted: 17 March 2020; Published: 20 March 2020

\begin{abstract}
Maximum Power Point Tracking (MPPT) control is an essential part of every photovoltaic (PV) system, in order to overcome any change in ambient environmental conditions and ensure operation at maximum power.. Recently, micro-inverters have gained a lot of attention due to their ability to track the true MPP for each individual PV module, which is considered a powerful solution to overcome the partial shading and power mismatch problems which exist in series-connected panels. Although the LLC resonant converter has high efficiency and high boosting ability, traditional MPPT techniques based on Pulse Width Modulation (PWM) do not work well with it. In this paper, a fixed frequency predictive MPPT technique is presented for the LLC resonant converter to be used as the first-stage in a PV micro-inverter. Using predictive control enhances the tracking efficiency and reduces the steady state oscillation. Operation with fixed switching frequency for the LLC resonant converter improves the total harmonic distortion profile of the system and ease the selection of circuit magnetic component. To demonstrate the effectiveness of the proposed MPPT technique, the system is simulated using MATLAB/Simulink platform. Furthermore, a $150 \mathrm{~W}$ hardware prototype is developed and tested. Both simulation and experimental results are consistent and validate the proper operation of the developed system.
\end{abstract}

Keywords: micro-inverter; LLC resonant converter; MPPT; phase-shift control; fixed frequency

\section{Introduction}

Photovoltaic (PV) cells are one of the promising kinds of renewable energy. The compound annual growth rate (CAGR) of PV installations was 36.8\% between the years 2010 to 2018 [1,2]. It is worth noting that the annual installation of PV stations in 2017 alone was the same as the total PV capacity until the end of 2012 [3]. It is expected that renewable power capacity will continue to increase by 50\% between 2019 and 2024 [4]. PV systems have different classifications, but they could be classified according to grid integration into [5-7]:

(1) Stand-alone PV systems (off-grid), and

(2) Grid-connected PV systems.

In the stand-alone (off-grid) mode, the PV system is isolated from the main grid, and hence the PV-voltage is converted to AC-voltage to feed AC-loads. Battery storage is an essential component 
in off-grid PV systems, in order to feed essential loads during emergencies [8]. There are different categories of storage systems like lead acid batteries. For example, the usage of supercapacitors is a good solution in case of limited energy storage capacity [9]. On the other hand, when the storage station is not able to cover all load demands, a hybrid system can represent a good solution [10]. Hybrid system using PV generation and hydrogen energy storage system is presented in [11].

In grid integrated PV systems, the PV panels are connected to the grid via a DC/AC converter. The grid voltage is fixed, and hence, the PV system is working as a current source which is injecting a sinusoidal current into the grid. The different formations which are developed in the literature for grid-tied PV systems are summarized as follows:

(i) Centralized PV arrays, where a huge number of PV panels are connected in series and parallel configuration and then they are connected to a centralized DC/AC converter. This configuration is commonly used in very high power PV plants. However, this system requires expensive switches and high voltage wiring [12], and in case of partial shading or mismatches, the system fails to extract the maximum power $[12,13]$.

(ii) Multi-string inverter. This configuration is used in medium power PV power plants. Strings are connected in parallel and each group of the parallel string is connected to their own DC-DC converter. All these converters are connected to the utility grid through a central DC/AC converter. Partial shading problems have less effect than in the centralized formation case, however as it still depends on a centralized inverter, inverter failures can shut down the whole plant [13].

(iii) Micro-inverter. This configuration is well suited for low power PV applications, where each PV panel has its own DC/AC converter [14-16]. Such a formation overcomes partial shading and power mismatch problems. Due to their compactness and high efficiency, micro-inverters have gained a lot of attention in grid-tie applications [17-19]. The main advantage of using a micro-inverter is that each PV module has its own power conversion, and hence independent MPPT control. Consequently, a global MPPT system is not required, as each PV module is operating at its maximum power in an independent way. Micro-inverters can be classified into single-stage micro-inverters and two-stage microinverters [20]. Two stage micro-inverters consist of DC-DC converters to perform voltage boosting and MPPT extraction and DC-AC converter to convert the DC voltage into AC voltage, while single stage micro-inverters consist of only one stage that performs voltage boosting, MPPT tracking and converts the DC voltage into AC voltage.

The general structure of a micro-inverter is illustrated in Figure 1. The general requirements of micro-inverters include the ability to operate at high efficiency, high power density and operation over a wide range of dynamic load changes [21]. The first stage of a micro-inverter is constituted by a DC-DC converter. Different types of DC-DC converters are described in the literature, but the high frequency (HF) resonant converter has small-size magnetic components, galvanic isolation, and higher efficiency over a wide load range. Such features make resonant converters a perfect choice for micro-inverter applications. Soft switching techniques are applied to the resonant converter to improve the overall system efficiency and reduce the switching losses of the system. Micro-inverter topologies can be classified into isolated micro-inverters and non-isolated micro-inverters. In non-isolated micro-inverters, the configuration does not include any transformer and the DC/DC stage is used such as boost, buck-boost or cuk converters [22-24]. Isolated micro-inverters include a transformer, high frequency or line frequency transformer, such as current-feed push-pull $[25,26]$, flyback converters [27,28], matrix converters $[29,30]$ and resonant converters [31-34]. Converters operating in soft switching mode are preferred more than hard-switching converters. Hard-switching causes higher switching losses, lower efficiency and damage to the switching devices. Resonant converters represent a superior solution for PV applications due to their high efficiency and zero-voltage switching (ZVS) and/or zero-current switching (ZCS) operation [35,36].

Different MPPT techniques for PV applications have been reported in the literature like perturb and observe (P\&O), incremental conductance (INC), or fuzzy logic MPPT. MPPT techniques based on predictive control have been introduced in [37-40]. Fixed-frequency fixed-step INC predictive 
MPPT proposed in [37] with an enhancement of the ordinary INC method by predicting the error before applying the switching signal. In [38], a variable-frequency fixed-step P\&O predictive control method was implemented with a good dynamic response and small power ripple at steady state, while a variable step size sensorless predictive MPPT was proposed in [39]. In [40], a predictive MPPT is presented for a Z-source grid-connected inverter using variable frequency control. All the previously mentioned techniques are implemented for PWM converters, but none of them could be applied directly to resonant topologies. Due to the nonlinearity of the voltage gain versus frequency relationship, MPPT with a special design mast be considered for frequency-modulated LLC resonant converters. Most of the old MPPT methods have been modified to be compatibile with different resonant converters. A modified $\mathrm{P} \& \mathrm{O}$ for a resonant converter is presented in [41,42]. Although this method is easy, it has some limitations that can be summarized as: fixed-step P\&O delays the response of the system, and the long tracking time leads to an increase in power losses.

In [43] a fixed step P\&O variable frequency control method is proposed for the LLC resonant converter. Although it is a simple technique, it suffers from a long transient period. A variable step variable frequency MPPT control is implemented in [44], but it suffers from a wide range of harmonics and bigger EMI, due to its variable frequency operation. Also, the design of the magnetic component is a cumbersome operation; a phase-shift fixed-frequency modulation control is used to overcome those disadvantages $[44,45]$. The use of fixed-frequency modulation with the LLC resonant converter is first addressed in $[46,47]$, which use a fixed-frequency P\&O MPPT but with high steady state oscillation.

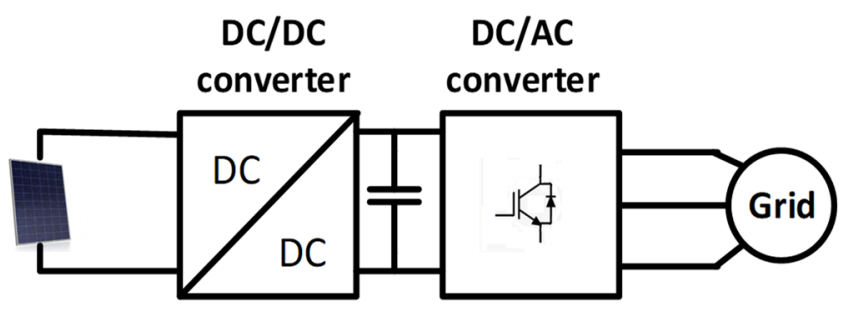

Figure 1. A two-stage PV grid-connected system.

This manuscript presents a novel fixed-frequency phase-shift (FFPS) predictive MPPT for LLC resonant converters to be used in the two-stage micro-inverter configuration for grid-tied PV applications. This manuscript modifies the content developed in [48], where the system is briefly discussed and only simple simulation results are included. On the other hand, here complete hardware results are presented, as well as an extensive system analysis.

The proposed fixed frequency predictive MPPT for LLC resonant converters has several advantages over other MPPT techniques suitable to be applied for tLLC resonant converters, which are as follows: (1) small steady state error due to the use of a PI controller. (2) Fast transient performance due to the prediction of reference voltage, and (3) simple parameter design due to the usage of fixed frequency modulation.The developed two-stage micro-inverter schematic is shown in Figure 2. It is constructed from a LLC resonant converter and an h-bridge inverter. This manuscript considers only the DC-DC part. The choice of the LLC resonant converter, the first stage in the proposed system, comes from its distinct features over other resonant converter topologies such as the ability to operate at ZVS/ZCS, wide input-voltage range, step-up ability, and high efficiency.

This paper is organized as follows: Section 2 discusses the analysis of LLC resonant DC/DC converter, then Section 3 discusses the proposed MPPT technique using the predictive Fixed-Frequency phase-shift control, Section 4 presents the simulation results for the proposed MPPT technique and experimental results, and finally Section 5 presents the experimental validation of the proposed MPPT technique. 


\section{Analysis of the LLC Phase-Shift Modulated Resonant Converter}

The LCC resonant converter depicted in Figure 2 consists of s phase-shift switching network, resonant tank, high frequency transformer, and voltage doubler. The switching network depends on the voltage gain requirements, and it may be constructed from a half-bridge or full-bridge. The switching network chops the input DC voltage into high-frequency square pulses. The resonant network consists of a series of $L_{s}$ and $C_{s}$, and $C_{p}$ in parallel with the rectifier input. The energy applied across the resonant tank by the switching network is circulated through the resonant tank network. Applied energy is delivered to the output either in the same or the next switching cycle.

The gating signal and key waveforms of the LLC resonant converter are shown in Figure 3. The converter is analyzed based on the fundamental harmonic approximation (FHA) technique given in [44]. The equivalent phasor circuit of the LLC converter is illustrated in Figure 4. The DC-input voltage is converted to a square wave waveform by the switching network. The output of the switched network appears between $X$ and $Y$ terminals. The root mean square (RMS) value of the fundamental component of the AC voltage $V_{X Y}$ is given by:

$$
V_{X Y}=\frac{\sqrt{2}}{\pi} V_{p v}(1-\cos \delta)
$$

where $\delta$ is the pulse width angle. it has an angle complementary to the phase shift angle $\alpha$ and $\alpha=\pi-\delta$ as shown in Figure 2. By using high switching transformer with turns ration $n$, the RMS value of primary voltage $V_{L p}$ can be obtained as:

$$
V_{L p}=\frac{1}{2} n V_{o}(a c)
$$

Then from (1) and (2):

$$
\frac{V_{L p}}{V_{X Y}}=(2 /(1-\cos \delta))\left(n V_{o}(a c) / V_{p v}\right)
$$

Referring to the phasor equivalent circuit of the converter in Figure 4, the following relation can be obtained:

$$
\frac{V_{L p}}{V_{X Y 1}}=\frac{1}{\left[\left\{1+\left(\frac{L_{s}}{L_{P}}\right)\left(1-F^{2}\right)\right\}^{2}+\left\{\frac{\pi^{2}}{8} Q\left(F-\frac{1}{F}\right)\right\}^{2}\right]^{\frac{1}{2}}}
$$

Thus from (3) and (4), the converter voltage gain $\mathrm{M}$ can be obtained by (5) as follows:

$$
M=\frac{n(1-\cos \delta) / 2}{\left[\left\{1+\left(\frac{L_{s}}{L_{P}}\right)\left(1-F^{2}\right)\right\}^{2}+\left\{\frac{\pi^{2}}{8} Q\left(F-\frac{1}{F}\right)\right\}^{2}\right]^{\frac{1}{2}}}
$$

where: $Q=\omega_{r} \frac{L_{s}}{R_{l}^{\prime}}, F=\frac{\omega_{s}}{\omega_{r}}=\frac{f_{s}}{f_{r}}, \omega_{s}=2 \pi f_{s}, R_{l}^{\prime}=\frac{R_{l}}{n^{2}}$.

Here $\omega_{r}=2 \pi f_{r}=1 / \sqrt{L_{s} C_{s}}$, and $R_{a c}=\left(\frac{8}{\pi^{2}}\right) R_{l}^{\prime} \cdot f_{s}$ refers to the switching frequency, and $f_{r}$ : is the resonant frequency. $V_{o}(\mathrm{ac})$ is the RMS of the output voltage. $\mathrm{V}_{x y 1}$ is the r.m.s. value of the output voltage of the inverter across terminals $\mathrm{XY}$. $R_{l}^{\prime}$ is the load resistance referred to primary-side. 


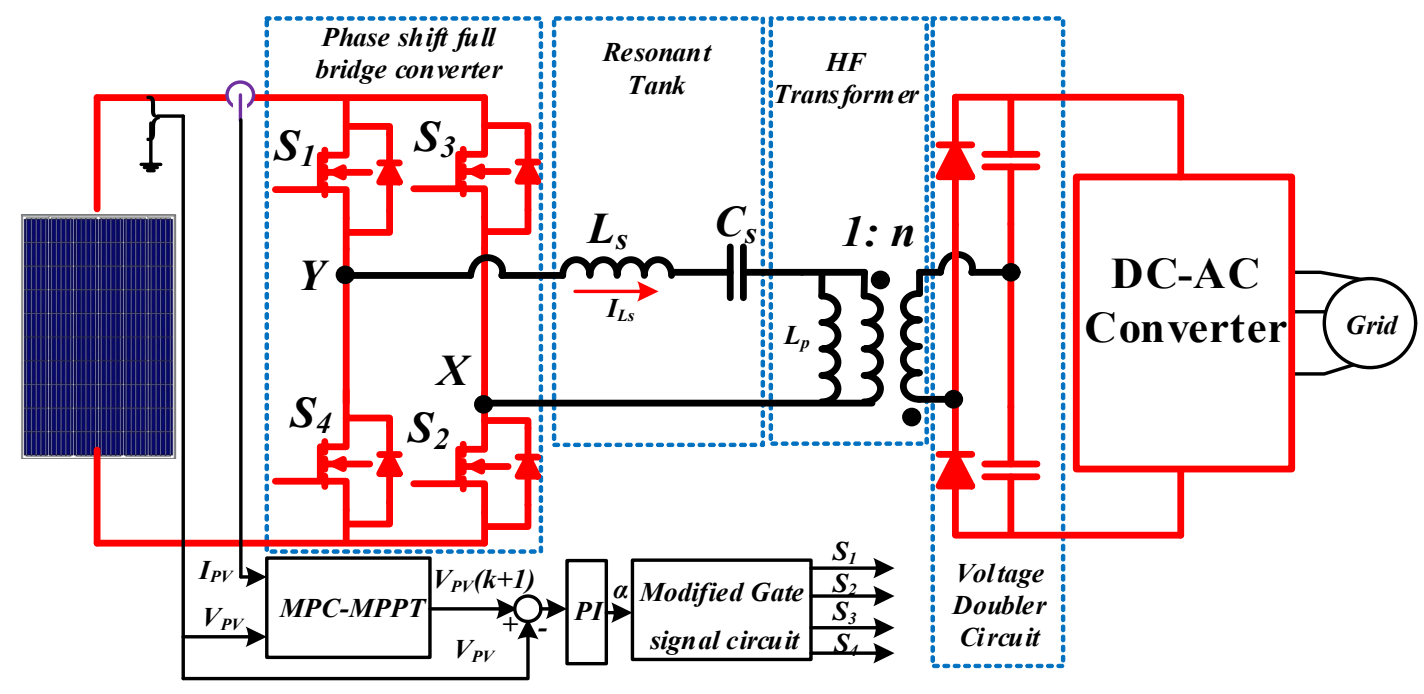

Figure 2. Proposed two-stage micro-inverter with LLC resonant converter.

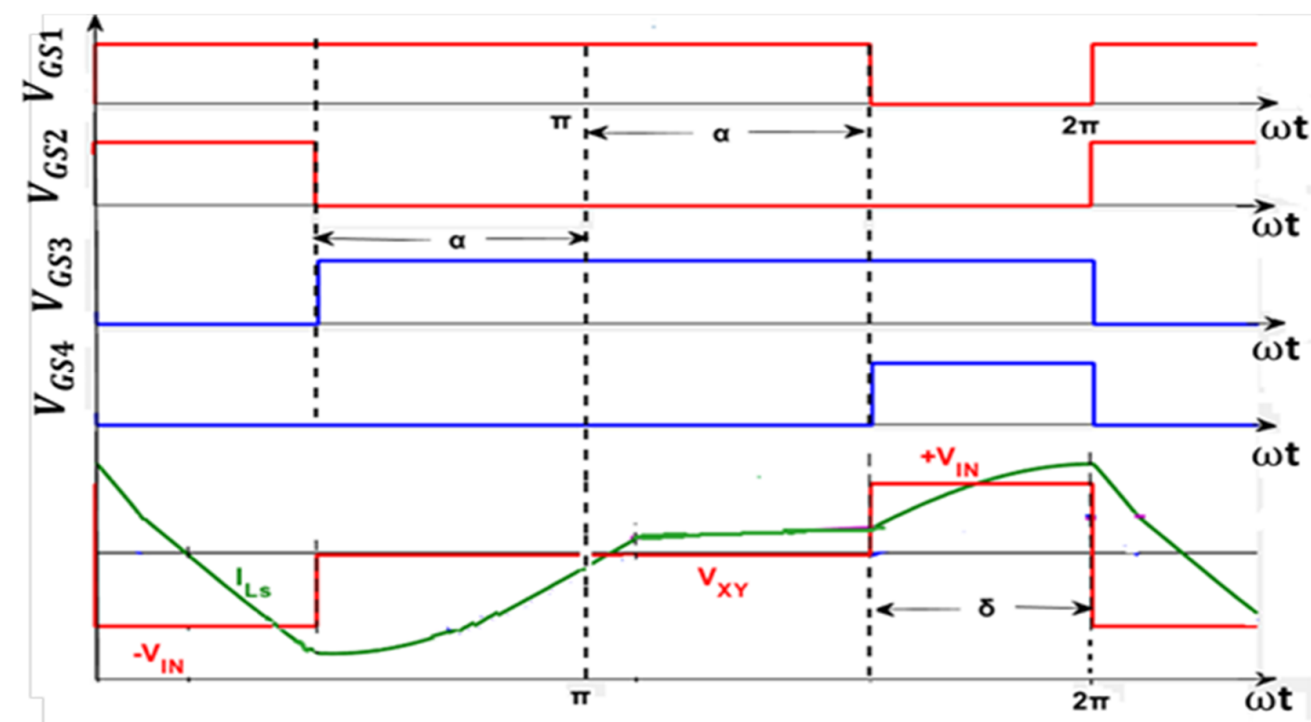

Figure 3. Switches gate signals voltage and current waveforms for the LLC resonant converter at arbitrary phase-shift.

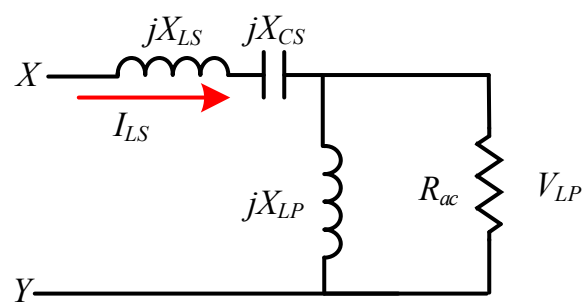

Figure 4. Phasor equivalent circuit for LLC resonant converter by using FHA. 


\section{Proposed Fixed-Frequency Phase-Shift Modulated MPC-MPPT Control}

Unlike the previously mentioned works, this manuscript presents a novel fixed frequency predictive maximum power point technique with an adaptive step-size for a phase-shift modulated LLC resonant converter. The schematic of the control feedback system is depicted in Figure 5.

The operation of the proposed methodology is performed in four steps, as follows:

Step 1: The PV terminals voltage value $V_{P V}(K)$, may be increased or decreased, depending on the applied switching state, during the next sampling time $(K+1)$, And hence the next sampling time of PV voltage $V_{P V}(K+1)$ is defined as:

$$
\left\{\begin{array}{l}
V_{P V}(K+1)_{1}=V_{P V}(K)+\Delta V \\
V_{P V}(K+1)_{2}=V_{P V}(K)-\Delta V
\end{array}\right.
$$

where $\Delta V$ is the step size. This step size could be set as a fixed value or could be designed to be variable according to change in the power level. A variable step size could be defined from the following equation:

$$
\Delta V=\sigma\left|P_{\max }(K+1)-P_{P V}(K)\right|
$$

where $\sigma$ is normalizing weigh factor, which is tuned to get good steady state performance by trial and error, $P_{\max }(K+1)$ is the next sampling time predicted maximum extracted PV power, the steps for calculating the value of $P_{\max }(K+1)$ will be explained in this section later. However, at starting an initial value of $\Delta \mathrm{V}$ can be set.

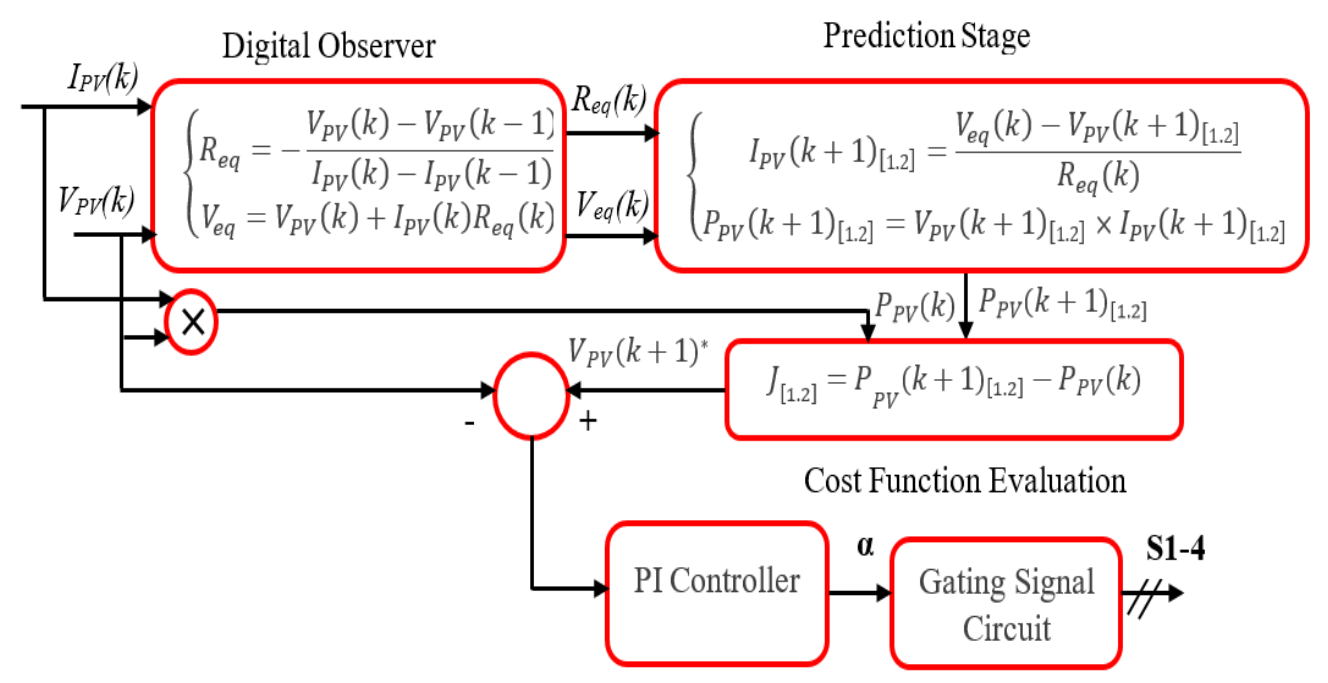

Figure 5. Block diagram of the proposed fixed frequency phase-shift MPPT predictive control.

Step 2: The next sampling time of the PV terminals voltage $V_{P V}(K+1)$ and the PV current $I_{P V}(K+1)$ are predicted. In order to reduce the number of sensors, a digital observer is used. Figure 6 presents the equivalent circuit of PV module using the Thevenin theorem. Designed digital observer is presented to calculate the required equivalent voltage $(V e q)$ and the equivalent resistance (Req) as follows:

$$
\begin{gathered}
R_{e q}=-\frac{\mathrm{V}_{P V}(k)-\mathrm{V}_{P V}(k-1)}{\mathrm{I}_{P V}(k)-\mathrm{I}_{P V}(k-1)} \\
V_{e q}=V_{P V}(\mathrm{k})+R_{e q} I_{P V(K)}
\end{gathered}
$$


Then the next sampling time predicted PV current can be calculated as:

$$
\left\{\begin{array}{l}
I_{P V}(K+1)_{1}=\frac{V_{e q}(K)-V_{P V}(K+1)_{1}}{R_{e q}(K)} \\
I_{P V}(K+1)_{2}=\frac{V_{e q}(K)-V_{P V}(K+1)_{2}}{R_{e q}(K)}
\end{array}\right.
$$

Step 3: Next the predicted next sampling time PV that can be extracted from the PV is calculated as follows:

$$
\left\{\begin{array}{l}
P_{P V}(K+1)_{1}=I_{P V}(K+1)_{1} \times V_{P V}(K+1)_{1} \\
P_{P V}(K+1)_{2}=I_{P V}(K+1)_{2} \times V_{P V}(K+1)_{2}
\end{array}\right.
$$

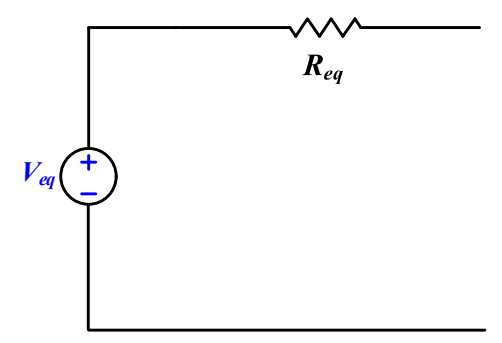

Figure 6. The Thevenin equivalent circuit of the PV module.

After calculating all possible output power of each switching state, during the next sampling time. Maximum power could be calculated as:

$$
P_{\text {max }}(K+1)=\operatorname{MAX}\left(P_{P V}(K+1)_{1}, P_{P V}(K+1)_{2}\right.
$$

Step 4: Then the cost function can be evaluated as:

$$
J_{[1,2]}=P_{P V}(K+1)_{[1,2]}-P_{P V}(K)
$$

After evaluation of the cost function by the proposed FFPS predictive MPPT to track the maximum available power from the PV, a reference voltage will be chosen for the next sampling period, that the larger value of cost function will be the next sampling time target, as example, if the cost function $J_{1}$ is greater than $J_{2}$, the PV voltage must be shifted to $V_{P V}(k+1)_{1}$, else if $J_{2}$ is greater than $J_{1}$ so the PV reference voltage will be $V_{P V}(k+1)_{2}$. PI controller is added to track the measured PV voltage with the predicted reference voltage. Prediction of the reference voltage improves the transient performance of the system, while using PI controller to track the reference voltage improves the steady state performance of the system.

\section{Simulation Results}

The operation of the proposed predictive MPPT technique is validated using a $300 \mathrm{~W}$ MATLAB/ Simulink model. The input voltage was changed over a wide range from $25 \mathrm{~V}$ to $41 \mathrm{~V}$. The resonant frequency $F_{\mathrm{r}}$ is selected to be $140 \mathrm{kHz}$, while switching frequency is set to $154 \mathrm{kHz}$. The resonant parameters are set to $4.1 / 3415 \mu \mathrm{H} / \mathrm{nF}$ for the resonant inductor and resonant capacitor, respectively. The transformer turns ratio is 1:7. The PV module used in the simulation has maximum power characteristics $(9.6 \mathrm{~A} / 31.25 \mathrm{~V})$. In order to demonstrate the superior behavior of the proposed technique, different operating condition are taken into account. Figure 7 illustrates a case of study of using fixed step-size, the irradiation level is set to $100 \%$ at the start, then, at time $t=0.7 \mathrm{~s}$, a reduction of the radiation level to $50 \%$ is applied as shown in Figure 7a. The proposed technique can extract maximum power. Figure $7 \mathrm{~b}, \mathrm{c}$ shows the change of the phase-shift to track the maximum power. 

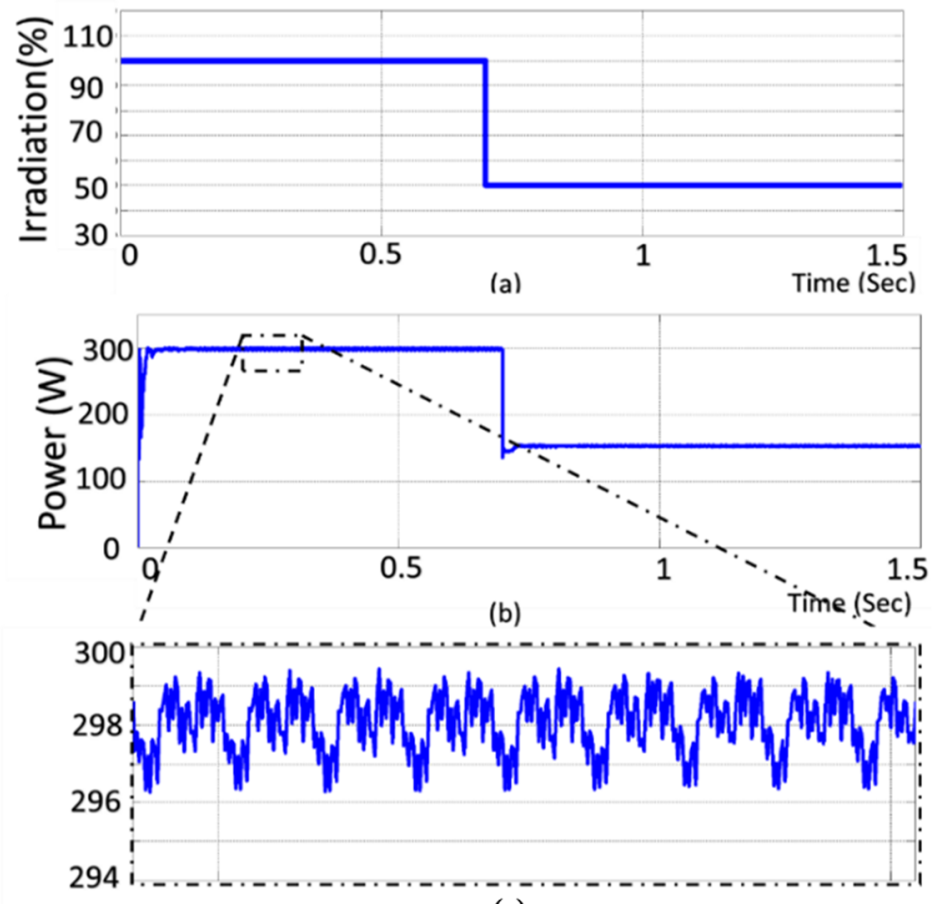

(c)

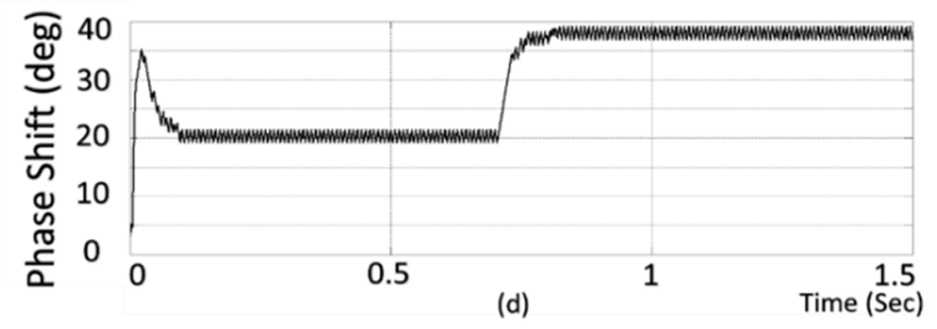

Figure 7. Proposed fixed-step FFPS predictive MPPT control: (a)the irradiation profile (b) the PV input power and the maximum power (c) the power oscillation (d) the phase-shift change.

Another case study is taken into account where a variable step-size FFPS predictive MPPT is considered. The results are depicted in Figure 8. The solar irradiation is shown in Figure 8a, the power extracted from the PV panel is shown in Figure 8b, as it is indicated in Figure 8c the oscillation around the MPPT is reduced with oscillations of less than $\pm 1 \%$.

Another simulation case study is depicted in Figure 9, where the solar irradiation was changed from $100 \%$ to $30 \%$ and then back again to $100 \%$ (Figure 9 a). As can be seen from Figure $9 b$, the FFPS predictive MPPT technique is able to extract the maximum power at all different conditions. The phase shift variation for this case study is depicted in Figure 9c. 

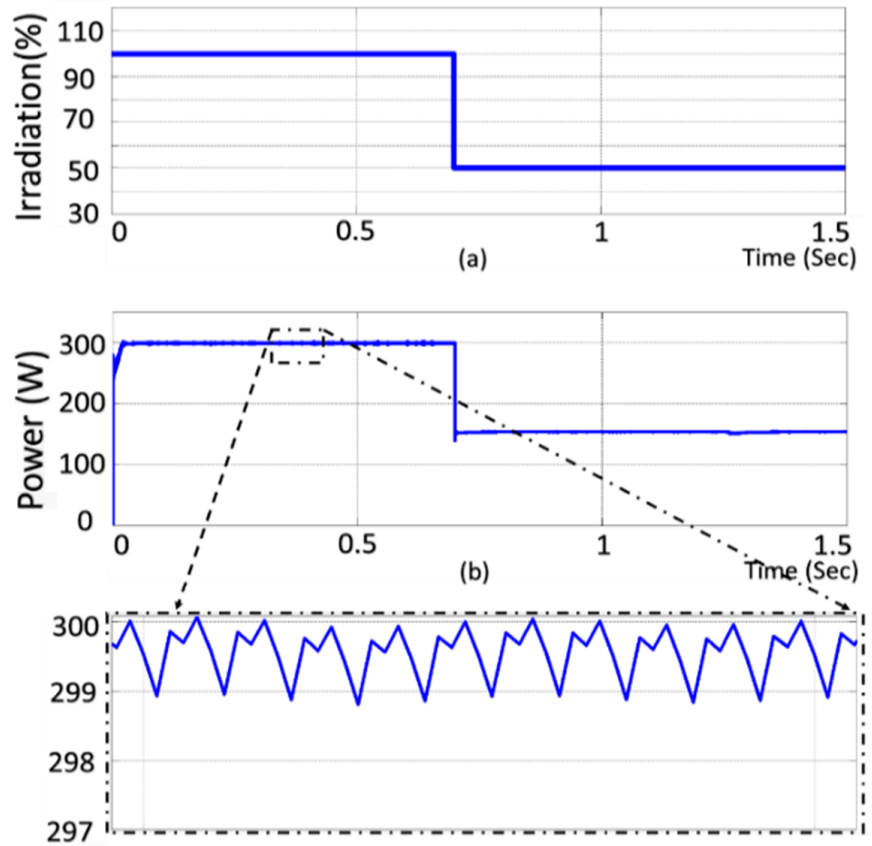

(c)

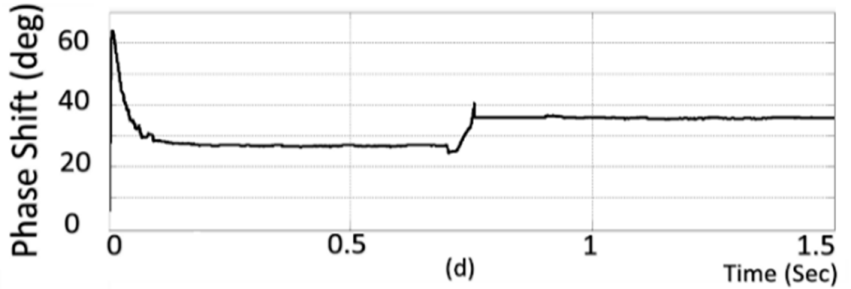

Figure 8. The proposed variable step FFPS predictive MPPT control: (a) the irradiation profile (b) the PV input power and the maximum power $(\mathbf{c})$ the power oscillation $(\mathrm{d})$ the phase-shift change.
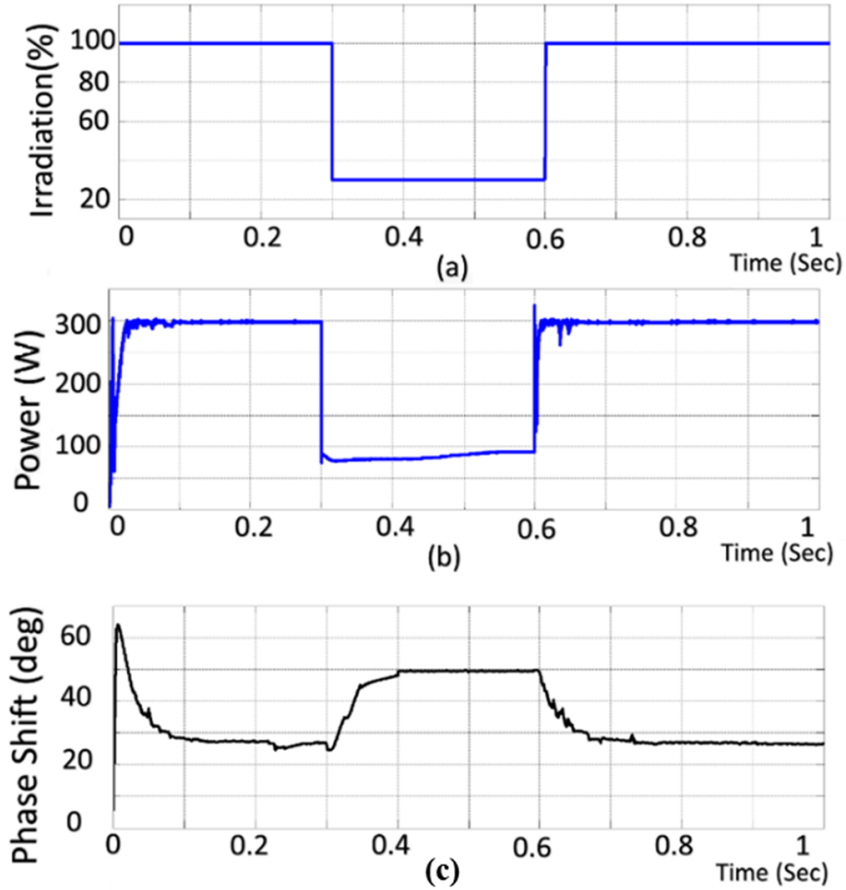

Figure 9. Irradiation step variation (100\%-30\%-100\%) with proposed FFPS predictive MPPT control: (a) the irradiation profile (b) the PV input power and the maximum power (c) the phase-shift change. 


\section{Experimental Results}

A laboratory prototype for the LLC resonant converter with its proposed FFPS Predictive MPPT technique was implemented. A general schematic for the hardware layout is depicted in Figure 10. It consists of a LLC resonant converter, TMS320F2835 DSP controller kit, and resistive load, in addition to the PV terminals. A JWP 250 PV module is used and the key parameters of the prototype hardware are listed in Table 1.

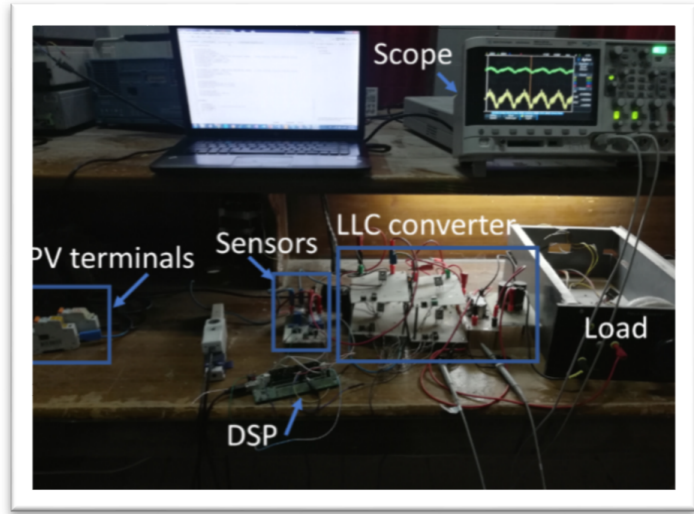

Figure 10. The experimental setup for the LLC resonant converter.

Table 1. Experimental prototype parameters.

\begin{tabular}{cc}
\hline Rated Power & $250 \mathrm{~W}$ \\
\hline Transformer Core Size & RM14 \\
\hline Turns Ratio & 7 \\
\hline Magnetizing Inductance & $20.5 \mu \mathrm{H}$ \\
\hline Switch S1-S4 & IRFB4510PBF \\
\hline Output Rectifier D1-D2 & QH03TZ600 \\
\hline
\end{tabular}

Different study cases have been investigated in the laboratory for the proposed FFPS predictive MPPT for the LLC resonant converter, and one of these cases is depicted in Figure 11. In this study case, the available maximum power from the real system is $100 \mathrm{~W}$. As can be seen from the graph, the proposed algorithm is efficiently able to extract the $100 \mathrm{~W}$ with efficiency around $99 \%$. The steady state oscillation for the proposed phase-shift MPPT technique is illustrated in Figure 12, where it is shown the power oscillates around the MPP within a $\pm 0.5 \mathrm{~W}$ range.

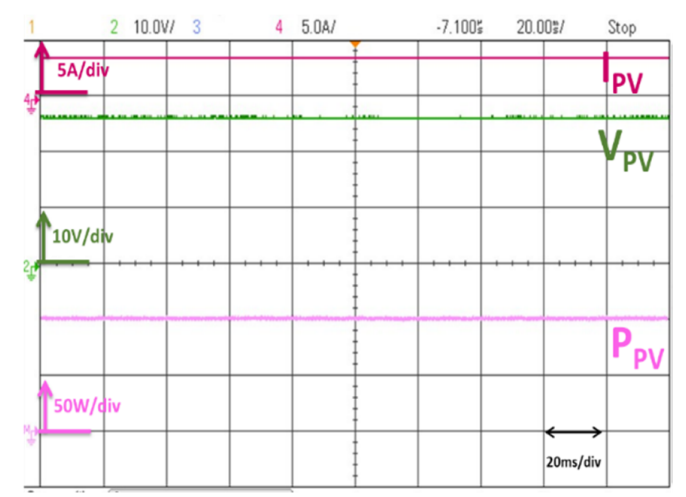

Figure 11. PV voltage current and power for the proposed fixed-frequency predictive MPPT $\left(\mathrm{P}_{\max }=100 \mathrm{~W}\right)(\mathrm{Ch} 2$ (green) is PV voltage, Ch4 (pink line) is the PV current), the PV extracted power (lavender line). 


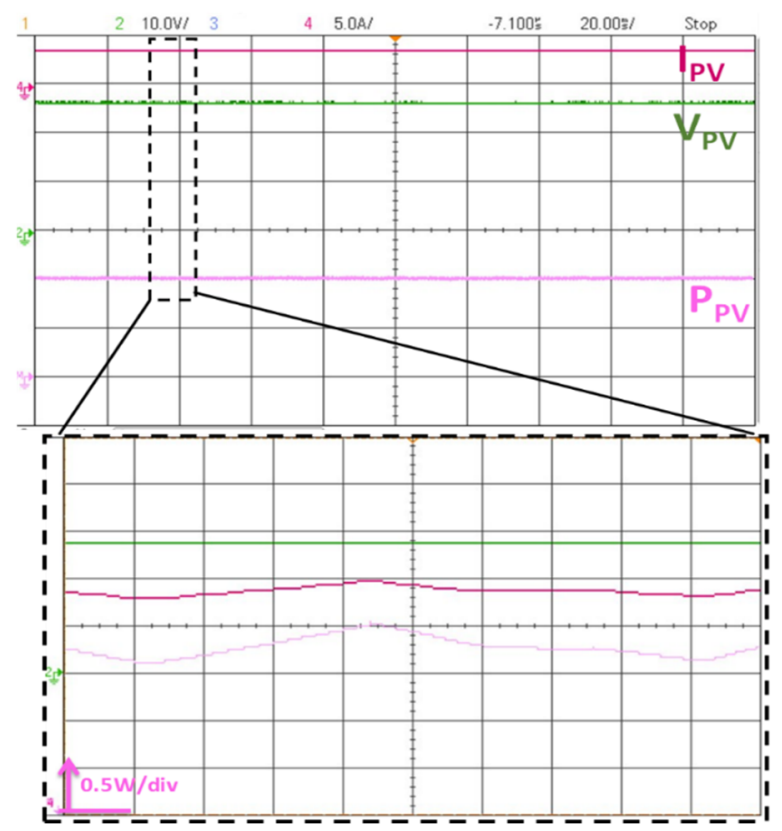

Figure 12. Steady state PV power oscillations for the proposed fixed-frequency predictive MPPT (Ch2 (green) is PV voltage, Ch4 (pink line) is the PV current), the PV extracted power (lavender line).

Another experimental case study is depicted in Figure 13. In this study case, the available maximum power from the real system is $115 \mathrm{~W}$. As can be seen from the graph, the proposed algorithm is efficiently able to extract the $115 \mathrm{~W}$ effectively.

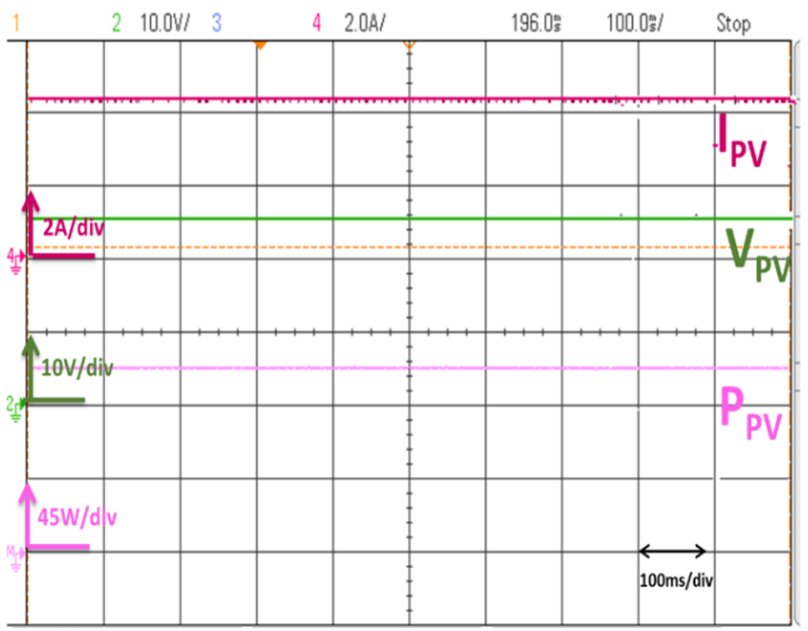

Figure 13. PV voltage current and power for the proposed Fixed-Frequency predictive MPPT $\left(\mathrm{P}_{\max }=115 \mathrm{~W}\right)(\mathrm{Ch} 2$ (green) is PV voltage, Ch4 (pink line) is the PV current), the PV extracted power (lavender line).

To prove the validity of the proposed MPPT technique under partial shading conditions and abrupt change in solar radiation conditions, a partial shading test and abrupt change in solar radiation test are performed, illustrated in Figures 14 and 15. In the partial shading case of study, depicted in Figure 14, a part of the real PV module is under lower radiation comditions. The radiation level and the maximum monitored available power were found to be $55 \mathrm{~W}$. As the figure demonstrates, the proposed MPPT algorithm extracts the real maximum power from the module with low oscillation and small transient time. Figure 15 depicts a case study where there is a sudden change in the solar radiation level, where the proposed MPPT technique able to track the maximum power with low oscillation and 
small transient time. A two-step test is performed and the result is shown in Figure 16, where partial shading conditions are formed by shading a part of the PV module, then this shading is removed, and as shown in the figure, the proposed fixed-frequency predictive MPPT effectively tracks the MPP.

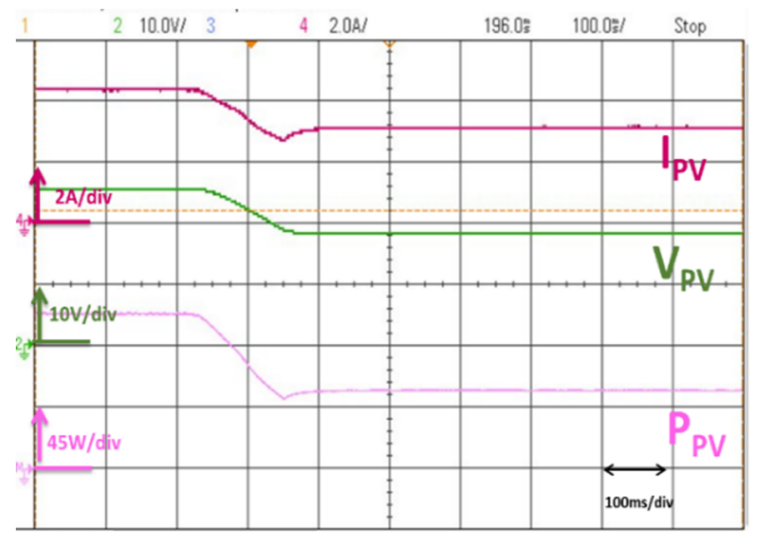

Figure 14. Proposed fixed-frequency predictive MPPT operation waveforms under partial shading condition (step down in the irradiation (Ch2 (green) is PV voltage, Ch4 (pink line) is the PV current), the PV extracted power (lavender line).

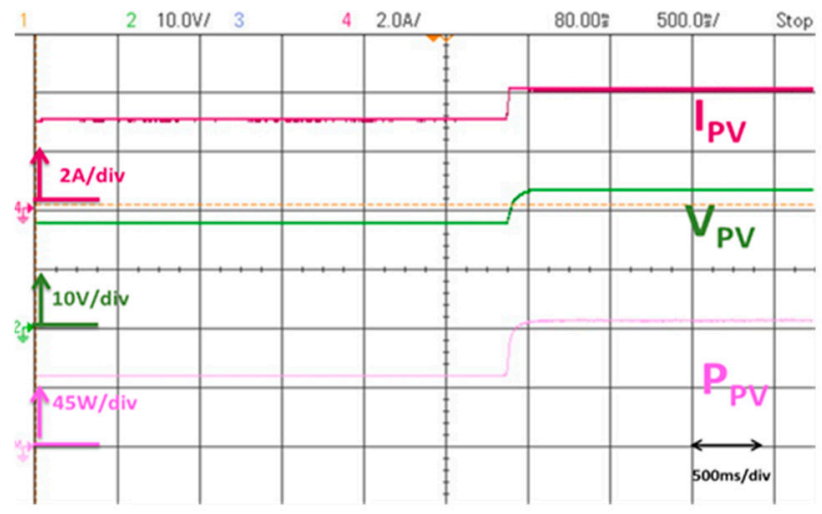

Figure 15. Proposed fixed-frequency predictive MPPT operation waveforms after removing the partial shading condition (step up in the irradiation) (Ch2 (green) is PV voltage, Ch4 (pink line) is the PV current), the PV extracted power (lavender line).

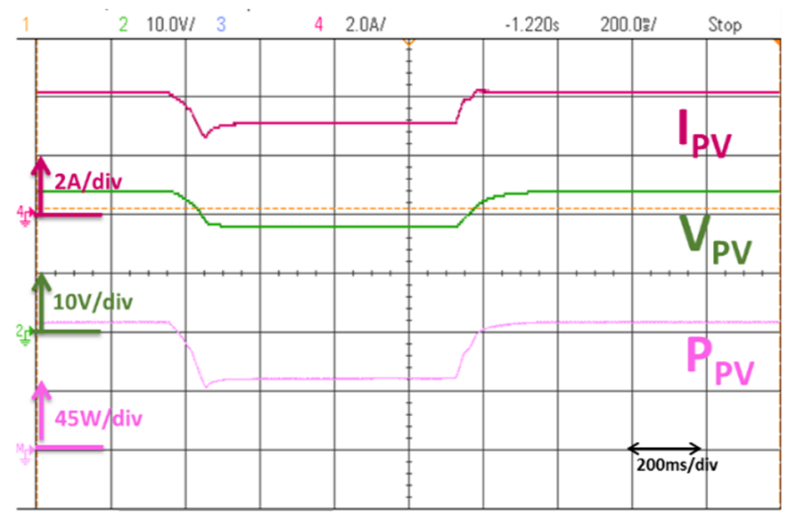

Figure 16. Proposed Fixed-Frequency Predictive MPPT operation waveforms under partial shading condition (two-step step down then step up in the irradiation) (Ch2 (green) is PV voltage, Ch4 (pink line) is the PV current), the PV extracted power (lavender line). 
The turn-on ZVS is indicated in Figure 17. During turning on the switch, its current should be negative by passing through the switch body diode. So that the switch capacitance is discharged and ZVS is achieved.

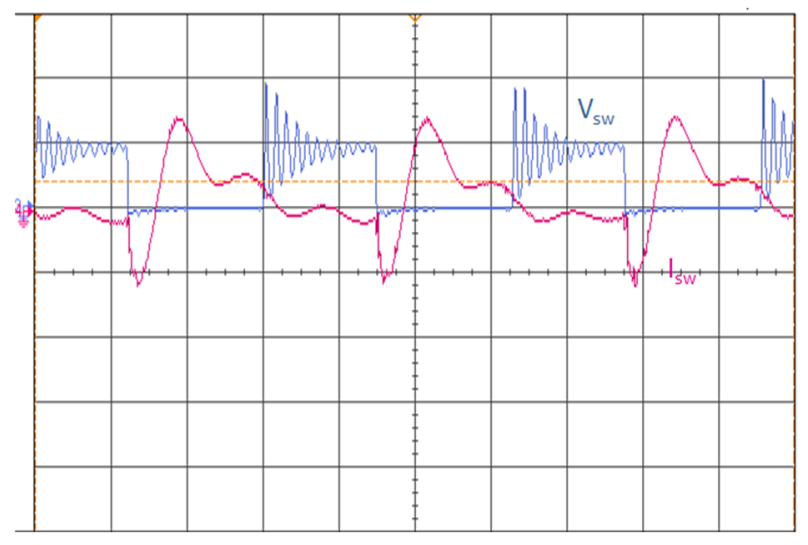

Figure 17. The turn on ZVS for the bridge.

\section{Conclusions}

This manuscript has presented a fixed frequency predictive-MPPT for phase-shift modulated LLC resonant converters for PV applications. Design steps for the control algorithm with the LLC resonant converter have been presented in a comprehensive way. The proposed FFPS predictive MPPT achieved the maximum available power from the PV module with an efficiency around 99\% and steady state oscillation around $\pm 0.5 \mathrm{~W} @ 115 \mathrm{~W}$. The proposed fixed frequency predictive MPPT for LLC resonant converters demonstrated several advantages over other MPPT techniques suitable to be applied to LLC resonant converters such as: (1) a small steady state error due to the use of a PI controller. (2) Fast transient performance due to prediction of the reference voltage, and (3) a simple parameter design due to the usage of fixed frequency modulation. A $300 \mathrm{~W}$ simulation model was implemented, then a $250 \mathrm{~W}$ hardware step-up was tested. Both simulation and hardware results are consistent and proved the high performance of the proposed predictive MPPT algorithm for LLC resonant converters.

Author Contributions: O.A.-R., M.A.I., N.A. and M.A., conceived, designed, implemented the proposed control strategy, and wrote the manuscript. M.O. and R.K. were responsible for guidance and a number of key suggestions. All authors have read and agreed to the published version of the manuscript.

Funding: This work is supported in part by the Egyptian Science and Technology Development Funds (STDF) and German Academic Exchange Service (DAAD) under German Egyptian Mobility Program For Scientific Exchange and Excellence Development (GE-SEED) ID: 30290.

Acknowledgments: This work was supported by the German Research Foundation (DFG) and the Technical University of Munich (TUM) in the framework of the Open Access Publishing Program. This work is supported in part by the Egyptian Science and Technology Development Funds (STDF) and German Academic Exchange Service (DAAD) under German Egyptian Mobility Program For Scientific Exchange and Excellence Development (GE-SEED) ID: 30290. Any opinions, findings, and conclusions or recommendations expressed in this material are those of the author(s) and do not necessarily reflect the views of the funding agencies.

Conflicts of Interest: The authors declare no conflict of interest.

\section{References}

1. Fraunhofer, I.S.E. Photovoltaics Report, Tech. Rep. Nov. 2019. Available online: https://www.ise.fraunhofer.de/ content/dam/ise/de/documents/publications/studies/Photovoltaics-Report.pdf (accessed on 14 November 2019).

2. Jäger-Waldau, A. PV Status Report 2018. Available online: https://publications.jrc.ec.europa.eu/repository/ bitstream/JRC113626/pv_status_report_2018_online.pdf (accessed on 4 November 2018).

3. Global Market Outlook for Solar Power/2018-2022. Available online: https://www.solarpowereurope.org/ wp-content/uploads/2018/09/Global-Market-Outlook-2018-2022.pdf (accessed on 17 November 2017). 
4. Renewables 2019 Fuel Report-October 2019. Available online: https://www.iea.org/reports/renewables-2019 (accessed on 21 October 2019).

5. Kjaer, S.B.; Pedersen, J.K.; Blaabjerg, F. A review of single-phase grid-connected inverters for photovoltaic modules. IEEE Trans. Ind. Appl. 2005, 41, 1292-1306. [CrossRef]

6. Abdel-Rahim, O.; Funato, H.; Haruna, J. An efficient and high-gain inverter based on the 3s inverter employs model predictive control for PV. J. Electr. Eng. Technol. 2017, 12, 1484-1494.

7. Roman, E.; Alonso, R.; Ibanez, P.; Elorduizapatarietxe, S.; Goitia, D. Intelligent PV Module for Grid-Connected PV Systems. IEEE Trans. Ind. Electron. 2006, 53, 1066-1073. [CrossRef]

8. Parimita, M.; Muneer, T.; KolheSolar, M. Photovoltaic System Applications: A Guidebook for off-Grid Electrification; Springer: Berlin, Germany, 2015; p. 50.

9. Li, J.; Chen, Y.; Liu, Y. Research on a stand-alone photovoltaic system with a supercapacitor as the energy storage device. Energy Procedia 2012, 16, 1693-1700. [CrossRef]

10. Merei, G.; Berger, C.; Sauer, D.U. Optimization of an off-grid hybrid PV-Wind-Diesel system with different battery technologies using genetic algorithm. Sol. Energy 2013, 97, 460-473. [CrossRef]

11. Mohammed, O.; Amirat, Y.; Benbouzid, M.; Elbast, A. Optimal Design of a PV/Fuel Cell Hybrid Power System for the City of Brest in France; IEEEICGE: Sfax, Tunisia, 2014; pp. 119-123.

12. Kouro, B.W.S.; Abu-Rub, H.; Blaabjerg, F. Power electronics for renewable energy systems, transportation, and industrial applications. In Photovoltaic Energy Conversion Systems, 1st ed.; Wile: Hoboken, NJ, USA, 2014; Chart 7.

13. Meinhardt, M.; Cramer, G.; Burger, B.; Zacharias, P. Multi-string-converter with reduced specific costs and enhanced functionality. Sol. Energy 2001, 69, 217-227. [CrossRef]

14. Yang, Y.; Kim, K.A.; Blaabjerg, F.; Sangwongwanich, A. 1-Introduction, in Advances in Grid-Connected Photovoltaic Power Conversion Systems; Yang, Y., Kim, K.A., Blaabjerg, F., Sangwongwanich, A., Eds.; Woodhead Publishing: Cambridge, UK, 2019; pp. 1-13.

15. Ahmed, M.E.; Orabi, M.; AbdelRahim, O.M. Two-stage micro-grid inverter with high-voltage gain for photovoltaic applications. IET Power Electron. 2013, 6, 1812-1821. [CrossRef]

16. Kouro, S.; Leon, J.I.; Vinnikov, D.; Franquelo, L.G. Grid-Connected Photovoltaic Systems: An Overview of Recent Research and Emerging PV Converter Technology. IEEE Ind. Electron. Mag. 2015, 9, 47-61. [CrossRef]

17. Chen, L.; Amirahmadi, A.; Zhang, Q.; Kutkut, N.; Batarseh, I. Design and Implementation of Three-Phase Two-Stage Grid-Connected Module Integrated Converter. IEEE Trans. Power Electron. 2014, 29, 3881-3892. [CrossRef]

18. Çelik, Ö.; Teke, A.; Tan, A. Overview of micro-inverters as a challenging technology in photovoltaic applications. Renew. Sustain. Energy Rev. 2018, 82, 3191-3206. [CrossRef]

19. Orabi, M.; Ahmed, M.; Abdel-Rahim, O. A Single-stage High Boosting Ratio Converter for Grid-connected Photovoltaic Systems. Electr. Power Compon. Syst. 2013, 41, 896-911. [CrossRef]

20. Razi, A.; Hidayat, M.N.; Seroji, M.N. Microinverter Topology based Single-stage Grid-connected Photovoltaic System: A Review. Indones. J. Electr. Eng. Comput. Sci. 2018, 11, 645-651. [CrossRef]

21. Oriti, G.; Julian, A.L.; Bailey, T.D. PV power conditioning system with LLC resonant converter in DCM. In Proceedings of the 2014 IEEE Energy Conversion Congress and Exposition (ECCE), Pittsburgh, PA, USA, 14-18 September 2014; pp. 4262-4268.

22. Darwish, A.; Holliday, D.; Ahmed, S.; Massoud, A.M.; Williams, B.W. A Single-Stage Three-Phase Inverter Based on Cuk Converters for PV Applications. IEEE J. Emerg. Sel. Top. Power Electron. 2014, 2, 797-807. [CrossRef]

23. Abdel-Rahim, O.; Funato, H.; Haruna, J. A comprehensive study of three high gain dc-dc topologies based on cockcroft-walton voltage-multiplier for reduced power pv applications IEEJ Transactions on Electrical and Electronic Engineering(TEEE D). IEEJ Trans. 2018, 13, 642-651.

24. Liang, Z.; Guo, R.; Li, J.; Huang, A.Q. A High-Efficiency PV Module-Integrated DC/DC Converter for PV Energy Harvest in FREEDM Systems. IEEE Trans. Power Electron. 2011, 26, 897-909. [CrossRef]

25. Jang, S.; Won, C.; Lee, B.; Hur, J. Fuel Cell Generation System With a New Active Clamping Current-Fed Half-Bridge Converter. IEEE Trans. Energy Convers. 2007, 22, 332-340. [CrossRef] 
26. Bai, C.; Han, B.; Kim, M. Current-fed dual-half-bridge converter directly connected with half-bridge inverter for residential photovoltaic system. Sol. Energy 2018, 174, 108-120. [CrossRef]

27. Kasa, N.; Iida, T.; Liang, C. Flyback inverter controlled by sensorless current MPPT for photovoltaic power system. IEEE Trans. Ind. Electron. 2005, 52, 1145-1152. [CrossRef]

28. Hasan, R.; Mekhilef, S. Highly efficient flyback microinverter for grid-connected rooftop PV system. Sol. Energy 2017, 146, 511-522. [CrossRef]

29. Geury, T.; Pinto, S.; Gyselinck, J. Direct control method for a PV system integrated in an Indirect Matrix Converter-based UPQC. In Proceedings of the 2016 IEEE Smart Energy Grid Engineering (SEGE), Oshawa, ON, Canada, 21-24 August 2016; pp. 117-122.

30. Haque, M.M.; Wolfs, P.; Alahakoon, S. Dual active bridge and matrix converter based three-port converter topology for grid interactive PV-battery system. In Proceedings of the 2017 Australasian Universities Power Engineering Conference (AUPEC), Melbourne, VIC, Australia, 19-22 November 2017; pp. 1-6.

31. Yilei, G.; Zhengyu, L.; Zhaoming, Q. Three-level LLC series resonant DC/DC converter. IEEE Trans. Power Electron. 2004, 20, 781-789.

32. Beiranvand, R.; Rashidian, B.; Zolghadri, M.R.; Alavi, S.M.H. Using LLC Resonant Converter for Designing Wide-Range Voltage Source. IEEE Trans. Ind. Electron. 2011, 58, 1746-1756. [CrossRef]

33. Harischandrappa, N.; Bhat, A.K.S. A Fixed-Frequency \$LCL\$-Type Series Resonant Converter With a Capacitive Output Filter Using a Modified Gating Scheme. IEEE Trans. Ind. Appl. 2014, 50, 4056-4064. [CrossRef]

34. Cha, W.J.; Kwon, J.M.; Kwon, B.H. Highly efficient step-up DC-DC converter for photovoltaic micro-inverter. Sol. Energy 2016, 135, 14-21. [CrossRef]

35. Rashid, M.H.; Hui, S.Y.; Chung, H.S.H. 12-Resonant and Soft-Switching Converters. In Power Electronics Handbook, 4th ed.; Rashid, M.H., Ed.; Butterworth-Heinemann: Oxford, UK, 2018; pp. 339-383.

36. Salem, M.; Jusoh, A.; Idris, N.R.N.; Das, S.H.; Alhamrouni, I. Resonant power converters with respect to passive storage (LC) elements and control techniques-An overview. Renew. Sustain. Energy Rev. 2018, 91, 504-520. [CrossRef]

37. Abdel-Rahim, O.; Funato, H.; Haruna, J. Novel predictive maximum power point tracking techniques for photovoltaic applications. J. Power Electron. 2016, 16, 277-286. [CrossRef]

38. Metry, M.; Shadmand, M.B.; Balog, R.S.; Rub, H.A. High-efficiency MPPT by model predictive control considering load disturbances for photovoltaic applications under dynamic weather condition. In Proceedings of the IECON 2015-41st Annual Conference of the IEEE Industrial Electronics Society, Yokohama, Japan, 9-12 November 2015; pp. 004092-004095.

39. Metry, M.; Shadmand, M.B.; Balog, R.S.; Rub, H.A. A variable step-size MPPT for sensorless current model predictive control for photovoltaic systems. In Proceedings of the 2016 IEEE Energy Conversion Congress and Exposition (ECCE), Milwaukee, WI, USA, 18-22 September 2016; pp. 1-8.

40. Sajadian, S.; Ahmadi, R. Model Predictive-Based Maximum Power Point Tracking for Grid-Tied Photovoltaic Applications Source Inverter. IEEE Trans. Power Electron. 2016, 31, 7611-7620. [CrossRef]

41. Fang, X. Analysis and Design Optimization of Resonant DC-DC Converters. Doctoral Dissertation, University of Central Florida, Orlando, FL, USA, 2012.

42. Shahul, A.; Oommen, A.P.; Kuruvilla, J. PMPPT Based Resonant Converter for A Standalone Water Pumping System. Int. J. Eng. Appl. Sci. Technol. 2017, 2, 148-154.

43. Conesa, A.; Velasco, G.; Martinez, H.; Roman, M. LCLC resonant converter as maximum power point tracker in PV systems. In Proceedings of the 2009 13th European Conference on Power Electronics and Applications, Barcelona, Spain, 8-10 September 2009; pp. 1-9.

44. Zhang, Q.; Hu, C.; Chen, L.; Amirahmadi, A.; Kutkut, N.; Shen, Z.J.; Batarseh, I. A Center Point Iteration MPPT Method With Application on the Frequency-Modulated LLC Microinverter. IEEE Trans. Power Electron. 2014, 29, 1262-1274. [CrossRef]

45. Li, X.; Li, H.; Hu, G. Modeling of a fixed-frequency resonant LLC DC/DC converter with capacitive output filter. In Proceedings of the 2013 IEEE Energy Conversion Congress and Exposition, Denver, CO, USA, 15-19 September 2013; pp. 5456-5461.

46. Alamir, N.; Ismeil, M.A.; Orabi, M. New MPPT technique using phase-shift modulation for LLC resonant micro-inverter. In Proceedings of the 2017 Nineteenth International Middle East Power Systems Conference (MEPCON), Cairo, Egypt, 19-21 December 2017; pp. 1465-1470. 
47. Abdel-Rahim, O.; Alamir, N.; Orabi, M. Mohamed Ismeil Fixed-frequency phase-shift modulated PV-MPPT for LLC resonant converters. J. Power Electron. 2019, 20, 279-291.

48. Alamir, N.; Abdel-Rahim, O.; Ismeil, M.; Orabi, M.; Kennel, R. Fixed Frequency Predictive MPPT for Phase-Shift Modulated LLC Resonant Micro-Inverter. In Proceedings of the 2018 20th European Conference on Power Electronics and Applications (EPE'18 ECCE Europe), Riga, Latvia, 17-21 September 2018; pp. 1-9. 